\title{
Microarray Analysis of Serum mRNA in Patients with Head and Neck Squamous Cell Carcinoma at Whole-Genome Scale
}

\author{
Markéta Čapková, ${ }^{1,2}$ Jana Šáchová, ${ }^{2}$ Hynek Strnad, ${ }^{2}$ Michal Kolár̆, ${ }^{2}$ \\ Miluše Hroudová, ${ }^{2}$ Martin Chovanec, ${ }^{1,3}$ Zdeněk Čada, ${ }^{1}$ Martin Šteffl, ${ }^{1,2}$ Jaroslav Valach, ${ }^{4}$ \\ Jan Kastner, ${ }^{1}$ Čestmír Vlček, ${ }^{2}$ Karel Smetana Jr., ${ }^{3}$ and Jan Plzák ${ }^{1}$ \\ ${ }^{1}$ Department of Otorhinolaryngology and Head and Neck Surgery, 1st Faculty of Medicine, Charles University, \\ University Hospital Motol, Institute of Postgraduate Medicine, V Uvalu 84, 15006 Prague 5, Czech Republic \\ ${ }^{2}$ Academy of Sciences of the Czech Republic, Institute of Molecular Genetics, Department of Genomics and Bioinformatics, \\ Videnska 1083, 14220 Prague 4, Czech Republic \\ ${ }^{3}$ Institute of Anatomy, 1st Faculty of Medicine, Charles University, U Nemocnice 3, 12800 Prague 2, Czech Republic \\ ${ }^{4}$ Department of Stomatology, 1st Faculty of Medicine, Charles University, Kateřinská 32, 12108 Prague 2, Czech Republic
}

Correspondence should be addressed to Jan Plzák; jan.plzak@lf1.cuni.cz

Received 17 January 2014; Accepted 24 February 2014; Published 23 April 2014

Academic Editor: Jan Betka

Copyright (C) 2014 Markéta Čapková et al. This is an open access article distributed under the Creative Commons Attribution License, which permits unrestricted use, distribution, and reproduction in any medium, provided the original work is properly cited.

\begin{abstract}
With the increasing demand for noninvasive approaches in monitoring head and neck cancer, circulating nucleic acids have been shown to be a promising tool. We focused on the global transcriptome of serum samples of head and neck squamous cell carcinoma (HNSCC) patients in comparison with healthy individuals. We compared gene expression patterns of 36 samples. Twenty-four participants including 16 HNSCC patients (from 12 patients we obtained blood samples 1 year posttreatment) and 8 control subjects were recruited. The Illumina HumanWG-6 v3 Expression BeadChip was used to profile and identify the differences in serum mRNA transcriptomes. We found 159 genes to be significantly changed (Storey's $P$ value $<0.05$ ) between normal and cancer serum specimens regardless of factors including p53 and B-cell lymphoma family members (Bcl-2, Bcl-XL). In contrast, there was no difference in gene expression between samples obtained before and after surgery in cancer patients. We suggest that microarray analysis of serum cRNA in patients with HNSCC should be suitable for refinement of early stage diagnosis of disease that can be important for development of new personalized strategies in diagnosis and treatment of tumours but is not suitable for monitoring further development of disease.
\end{abstract}

\section{Introduction}

Head and neck squamous cell carcinoma (HNSCC) is the fifth most common cancer worldwide. The overall incidence is half a million cases per year. HNSCC accounts for about $10 \%$ of the total cancer burden in men [1]. Its biological behaviour is typified by aggressive locoregional invasiveness, local recurrence, and tumour multiplicity. Despite considerable advances in surgical and oncological treatment over the past two decades, overall disease outcome has only slightly improved. The main reason for this is late diagnosis, with almost two-thirds of cases being diagnosed in the late stage of disease. The presence of lymph node metastasis is associated with a $50 \%$ decrease in 5-year survival and is the single most important prognostic factor identified to date [2-5]. For better prognosis of patients and reduction of posttherapeutic morbidity, including significant discomfort, it is crucial to recognise the cancer at an early stage. Therefore, many scientists have dedicated much effort to identification of potential biomarkers involved in the process of carcinogenesis and investigation of the molecular characteristics of HNSCC.

The field of cancer research has continued to evolve rapidly, and, in recent years, there have been advances in our knowledge of the molecular biology and epigenetics 
of HNSCC as well as in the techniques available to study this disease. Development of high-throughput expressionarray-based techniques has led to the detection of novel tumour suppressor genes (TSGs) and protooncogenes, as well as a description of epigenetic modifications involved in tumourigenesis. Finally, the field of bioinformatics is now intimately involved in deciphering the data generated by these techniques. Many studies have yielded promising results in this field by analysing tumour tissue samples in comparison to normal mucosa [6-11]. However, assays based on processing of tumour tissue samples do not resolve the problem of early diagnosis, and invasive tumour biopsy places great demands on the patient and is limited in size.

With the increasing demand for noninvasive approaches in the monitoring of cancer, circulating nucleic acids (CNAs) have been shown to be a promising tool. In the case of neoplasia, circulating RNA has been found to be a more sensitive marker than tumour-derived circulating DNA. The first study associating circulating RNA in the serum as a potential tumour marker was reported by Wieczorek et al. more than 20 years ago. That study reported an association between the presence of the RNA-proteolipid complex and the tumour response to therapy [12]. During the past 10 years, there has been a great leap forward in detecting and testing isolated cell-free RNA for different tumour-related transcripts [13, 14], telomerase components [15], or viral RNA transcripts. Tumour-associated RNA was detectable in the serum or plasma of patients with breast, liver, or lung cancer [16], colorectal cancer [17], follicular lymphoma [18], prostate cancer [19], malignant melanoma [20], hepatocellular carcinoma, oesophageal carcinoma, and others [21, 22]. Unfortunately, almost no data are available on cRNA in patients with HNSCC. The detection and identification of cRNA can be carried out by using microarray technologies or reverse transcription quantitative real-time PCR [23].

Detection of cell-free RNA in plasma and serum could potentially serve as a "liquid biopsy," which would avoid the need for tumour tissue biopsies. This approach is especially favourable for its possibility of taking repeated blood samples during cancer development and progression, as well as during the monitoring of cancer treatment. Indeed the role of CNAs as blood biomarkers was recently highlighted [24].

\section{Materials and Methods}

Twenty-four participants including 16 HNSCC patients (from 12 patients we obtained blood samples 1 year after treatment) and eight control subjects were recruited. The Illumina HumanWG-6 v3 Expression BeadChip was used to profile and identify the differences in serum mRNA transcriptomes between cancer patients and healthy controls as well as the differences in serum mRNA transcriptomes between serum from the same donor obtained before surgery and 1 year after treatment.

2.1. Blood Specimens and Collection Procedure. The blood specimens were obtained from Department of Otorhinolaryngology and Head and Neck Surgery (Charles University,
First Faculty of Medicine, Prague, Czech Republic), with patient consent and approval of the Local Ethical Committee according to the principles of the Helsinki Declaration. The blood samples were obtained from patients with HNSCC who underwent surgical treatment and were drawn before surgery and then approximately 1 year after treatment. As healthy controls, we selected patients with benign noninflammatory diagnoses. The demographic and clinical data of cases and controls are shown in Table 1. All blood samples were processed within 2 hours after venous puncture. Blood was centrifuged at $1,000 \mathrm{~g}$ for 10 minutes at $4^{\circ} \mathrm{C}$, and $0.5-\mathrm{mL}$ aliquots of serum samples were stored at $-80^{\circ} \mathrm{C}$.

\subsection{RNA Extraction, Amplification, Labeling, and Hybridization}

Extraction. An aliquot of $400 \mu \mathrm{L}$ of each serum sample was used for RNA extraction. Total RNA was isolated by MagMAX Viral RNA Isolation Kit (Ambion Inc., Foster City, CA, USA) according to the manufacturer's recommendations. RNA quantity was measured on a NanoDrop 3300 fluorospectrometer (NanoDrop Technologies LLC, Wilmington, DE, USA). RNA integrity was assessed on an Agilent 2100 Bioanalyzer and RNA 6000 Pico LabChip (Agilent Technologies, Santa Clara, CA, USA).

Amplification. Total RNA was amplified using WT-Ovation One Direct RNA Amplification System V1.0 (NuGEN Technologies Inc., San Carlos, CA, USA), according to the standard protocol, from a starting amount of $500 \mathrm{pg}$. Amplified cDNA was consequently purified by MinElute Reaction Cleanup Kit (QIAGEN Inc., Valencia, CA, USA) according to the instructions described in the WT-Ovation One Direct protocol. RNA quality and quantity were assessed on an Agilent 2100 Bioanalyzer and RNA 6000 Pico LabChip.

Labeling. After purification, theamplified single-stranded cDNA was labeled with biotin according to the NuGEN Illumina Protocol.

Hybridization. Illumina HumanWG-6 v3 Expression BeadChip (Illumina, San Diego, CA, USA) was used for the microarray analysis following the standard protocol. Biotinlabeled cDNA $(1.5 \mu \mathrm{g})$ was hybridized, washed, and scanned according to the manufacturer's instructions, with the exception that the hybridization temperature was reduced to $48^{\circ} \mathrm{C}$ to accommodate the altered hybridization kinetics of cDNA/DNA pairs relative to cRNA/DNA pairs. All subsequent analyses were done on biological replicates.

2.3. Data Analysis. The raw data (TIFF image files) were analysed using the BeadArray package [25] of the bioconductor within the $\mathrm{R}$ environment ( $\mathrm{R}$ Development Core Team 2007). All hybridizations passed quality control. The data were background corrected and normalized with the probe level quantile method. The probes with intensity level lower than the 95 percentile of negative controls of the BeadChip in all samples were disregarded before 
TABLE 1: Demographic and clinical data of patients included in the study.

(a)

\begin{tabular}{|c|c|c|c|c|c|c|c|}
\hline Specimen & Gender & Age of diagnosis & Tumour site & Grade & $\mathrm{pT}$ & $\mathrm{pN}$ & Stage \\
\hline S12C, S12T & $\mathrm{F}$ & 42 & Tonsillar fossa & G2 & $\mathrm{T} 2$ & N3 & IV \\
\hline S14C, S14T & M & 61 & Larynx & G2 & T3 & No & III \\
\hline S15C, S15T & M & 59 & Tongue margin & G2 & T3 & N2 & IV \\
\hline S18C, S18T & M & 66 & Soft palate & G2 & $\mathrm{T} 1$ & No & I \\
\hline S20C, S20T & M & 63 & Soft palate & G2 & $\mathrm{T} 1$ & $\mathrm{~N} 2$ & IV \\
\hline S21C & M & 62 & Tonsillar fossa & $\mathrm{G} 2$ & $\mathrm{~T} 2$ & No & II \\
\hline S22C, S22T & M & 65 & Body of tongue & G2 & $\mathrm{T} 2$ & $\mathrm{~N} 2$ & IV \\
\hline S23C, S23T & M & 65 & Palatine tonsil & G1 & $\mathrm{T} 2$ & N1 & III \\
\hline S24C & M & 73 & Palatine tonsil & $\mathrm{G} 2$ & $\mathrm{~T} 2$ & $\mathrm{~N} 2$ & IV \\
\hline S29C, S29T & $\mathrm{F}$ & 61 & Larynx & G3 & $\mathrm{T} 4$ & No & IV \\
\hline S31C, S31T & M & 58 & Palatine tonsil & $\mathrm{G} 2$ & T3 & N3 & IV \\
\hline S33C, S33T & M & 69 & Root of tongue & G2 & $\mathrm{T} 2$ & N2 & IV \\
\hline S40C & $\mathrm{F}$ & 73 & Retromolar trigone & G1 & $\mathrm{T} 2$ & N2 & IV \\
\hline S42C, S42T & M & 76 & Piriform recess & G2 & $\mathrm{T} 3$ & No & III \\
\hline S43C, S43T & M & 70 & Palatine tonsil & G2 & $\mathrm{T} 2$ & N2 & IV \\
\hline S66C & $\mathrm{M}$ & 51 & Body of tongue & G1 & $\mathrm{T} 1$ & No & $\mathrm{I}$ \\
\hline
\end{tabular}

(b)

\begin{tabular}{lccc}
\hline Specimen & Gender & Age of diagnosis & Diagnosis \\
\hline S01H & M & 29 & Negative \\
S02H & M & 74 & Cystitis sinus maxillaris \\
S03H & F & 41 & Hypacusis conductiva \\
S04H & F & 25 & Perforation myringitis \\
S05H & F & 48 & Perforation myringitis \\
S06H & F & 59 & Atherosclerosis \\
S07H & M & 32 & SAS \\
S08H & M & 26 & Cystitis colli lateralis \\
\hline
\end{tabular}

detection of differential expression. Differential expression was performed with the Limma package [26] on intensities that were variance-stabilized by logarithmic transformation. Annotation provided by bioconductor was used (illuminaHumanv3BeadID.db) [27]. Only transcripts with a false discovery rate (FDR) $<0.05$ and fold change $<0.5$ or $>2$ were reported and used in the downstream analysis. To identify significantly perturbed pathways, we performed SPIA [28] analysis on KEGG pathways: genes with FDR $<0.05$ were considered to be differentially transcribed. The data were deposited in the ArrayExpress database under accession number E-MTAB-1516.

\section{Results}

3.1. Comparison of Serum Expression Profiles of HNSCC Patients and Healthy Individuals. The global gene expression pattern of the blood samples was analysed using principal component analysis (PCA). In this analysis all 16 HNSCC serum specimens were grouped together and were distinct from the normal specimens, showing that the pattern of gene expression was different in cancer patients and healthy individuals (Figures 1(a) and 1(b)).
1055 gene transcripts were significantly changed $(P<$ 0.05 , with at least a twofold change between normal and cancer serum specimens); see Supplementary Tables S1 and S2 (see Tables S1 and S2 in the Supplementary Material available online at http://dx.doi.org/10.1155/2014/408683/). After correction to FDR (false discovery rate), we obtained 159 gene transcripts that were significantly changed ( $P$ value $<0.05)$. Among these genes, we found the following groups as the most interesting: genes involved in the p53 signalling pathway (p53, p21, cyclinD, MDM2, CASP3, and MAX) and genes of the B-cell lymphoma (Bcl-2) family of proteins (Bcl2, Bcl-XL, Bcl2L1, Mcl1, and BclAF1).

3.1.1. Deregulated Myc Expression in HNSCC Patients. We found deregulated Myc expression (MAX: Myc associated factor $\mathrm{X}, P=0.0099, \log \mathrm{FC}=1.77$ in the cancer-control group and $P=0.0055, \log \mathrm{FC}=2$ in the treated-control group) and upregulation of proapoptotic transmembrane protein Bim in different isoforms (TMBIM4 (transmembrane BAX inhibitor motif containing 4$), P=0.019, \log \mathrm{FC}=1.78$, and TMBIM1, $P=0.024, \log \mathrm{FC}=1.69$ in the cancer-control group and TMBIM4, $P=0.078, \log F C=1.36$ and TMBIM1, $P=0.038, \log \mathrm{FC}=1.61$ in the treated-control group). 


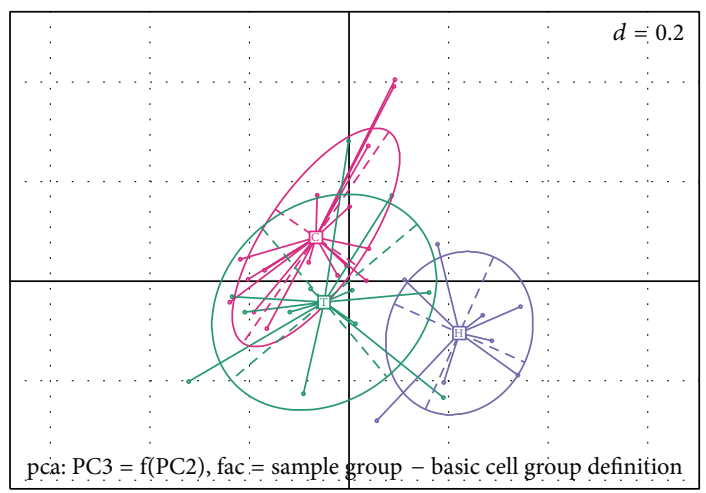

(a)

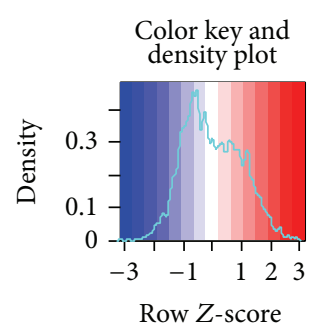

M: contrast $\mathrm{CH}, 140$ probes (eSet.rmb), $q<0.05$ and $\mathrm{FC} \geq 2$, sampled if $>1000$
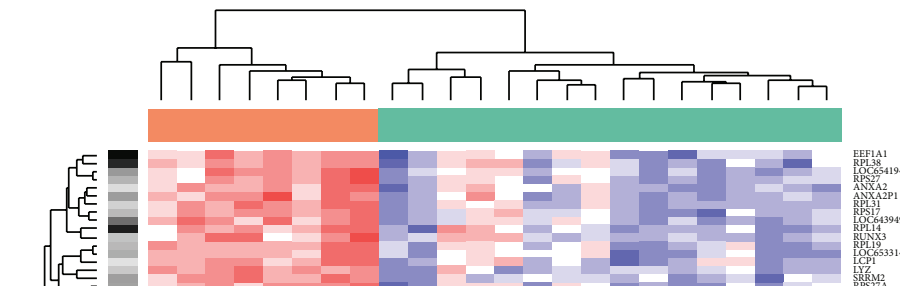
3.1.2. Differences in Gene Expression in HNSCC Patient Serum before and 1 Year after Treatment. We compared 12 HNSCC serum samples from the same donors before and 1 year after treatment. The global gene expression analysis showed 246 changed genes $(P<0.05$, with at least a twofold change). However, there were no significantly changed genes after FDR correction, demonstrating that the changes were less than those between cancer and normal serum samples.

3.1.3. Signalling Pathway Analysis. Genes that were differentially expressed $(P<0.05)$ were analysed using signalling pathway impact analysis (SPIA) of the KEGG pathways. This combines the evidence obtained from the classical enrichment analysis with a novel type of evidence, which measures the actual perturbation on a given pathway under a given condition. In our dataset we were able to identify the pathways that were differentially activated or inhibited (FDR < 0.05 ) in serum of cancer patients and healthy individuals. The pathways that were significantly activated in our dataset were connected with antigen processing and presentation, focal adhesion, viral carcinogenesis, regulation of actin cytoskeleton, and chemokine signalling pathway or were involved in several viral infections (e.g., herpes simplex, influenza A, human T-lymphotrophic virus-I, and viral myocarditis). By contrast, the significantly inhibited pathways involved RNA transport, leukocyte transendothelial migration, naturalkiller-cell-mediated cytotoxicity, and pathways connected with some neurodegenerative or autoimmune diseases (e.g., Parkinson's disease, Huntington's disease, and rheumatoid arthritis) (Table 2).

These findings were further supported by gene set enrichment analysis (GSEA) on the KEGG pathways, which showed significant deregulation of related pathways and downregulation of pathways connected with overall metabolism, RNA transport and degradation, and similar neurodegenerative diseases (Supplementary Table S3).

Using GSEA on GO (gene ontology) terms, we found that the following influenced the biological processes: translational processes; ribosomal biogenesis; viral transcription; negative regulation of DNA damage response-signal transduction by p53 class mediator; induction of apoptosis; and several integrin- or interferon-mediated pathways. In terms of cellular compartment we detected changes mainly in the cytosolic or nuclear compartment (Supplementary Tables S4 and S5).

\section{Discussion}

Carcinogenesis and tumour progression are complex and progressive processes that are associated with numerous genetic and epigenetic alterations that can be detected in plasma or serum. Although there is a long history of investigation of circulating mRNA as a potential biomarker, not many relevant studies have used whole-genome microarray profiling $[29,30]$. The aim of many microarray experiments is to determine the global genetic alterations that distinguish cancer cells from their normal counterparts. In our previous studies we mainly focused on the global transcriptome of cancer tissues in comparison with normal epithelium and especially peritumoural tissue. We have shown that paracrine secretion of growth factors, such as insulin-like growth factor-2 (IGF-2) and bone morphogenetic protein-4 (BMP4), can elucidate the biological activity of stromal fibroblasts to normal keratinocytes by markedly influencing their phenotype. The induced keratinocytes acquire the appearance of squamous cell carcinoma keratinocytes or keratinocytes of wounded skin [31-35].

In light of these experiments, we tried to focus on markers that could potentially be present in the serum of cancer patients. There are several theories about how CNAs are released into the bloodstream. CNAs enter the bloodstream after apoptosis of nucleated cells or after tumour necrosis or are actively released into the circulation by tumour cells [36-38]. We need to realize that the changes in the different transcripts in the serum arise from a heterogeneous cell population-tumour cells, nucleated cells such as lymphocytes or monocytes, as well as a small number of thrombocytes. That is why we can expect changes in genes connected with cell death and tumour suppression, proliferation, and differentiation. There have been several studies using wholegenome microarray profiling to detect differences in serum gene expression in different types of solid tumours [39-42] as well as haematopoietic malignancies [43-45]. In our present study we adopted a similar design using whole-genome microarray profiling. What was particularly interesting was the combination of three different groups of samples, from patients before and after treatment as well as from healthy individuals.

As in numerous previous studies, we found that the apoptotic pathway was altered in the patients. Apoptosis is a major barrier to oncogenesis $[46,47]$ and is triggered by several factors that act through two major pathways: extrinsic and intrinsic pathways $[48,49]$. In vertebrates most apoptosis proceeds through the intrinsic pathway. A regulator of this process is the Bcl-2 family of proteins [50]. The family comprises both antiapoptotic or prosurvival members (which can be divided into two subclasses: Bcl-2, Bcl-XL, and $\mathrm{Bcl}-\mathrm{W}$ and $\mathrm{Mcl}-1$ and $\mathrm{Al}$ ) and proapoptotic members (the BAX subfamily that includes BAX, BAK, and BOK and the BH3-only subfamily that includes BID, BIM, BAD, BIK, BMF, PUMA, NOXA, and HRK) [51, 52]. The balance between these proteins determines whether a cell commits apoptosis, and the main regulator of these processes is p53. The identification of a myriad of proapoptotic p53 targets that bind and inhibit antiapoptotic Bcl-2 family members suggests that it is only through the combined transcriptional activation of numerous proapoptotic targets that p53 exerts its full apoptotic capability. Similarly, a combination of p53-dependent and -independent signals establishes a total apoptotic burden in a cell that stands in opposition to the prosurvival function of Bcl-2. In our study we revealed significant difference in presence of p53 transcripts in serum of cancer-control group gene expression of p53 in cancercontrol group $(P=0.00031 ; \operatorname{logFC}=-2.24)$ and in treatedcontrol group $(P=0.019$; $\log \mathrm{FC}=-1.79)$, respectively. In contrast, we did not find a significant difference in expression in the cancer-treated group. As far as Bcl-2 family proteins are 
TABLE 2: SPIA comparison of cancer serum specimens and healthy individuals serum specimens shows significant upregulation of pathways involved in antigen processing and presentation, focal adhesion, viral carcinogenesis, regulation of actin cytoskeleton, and downregulation of pathways involved in RNA transport, leukocyte transendothelial migration, natural-killer-cell-mediated cytotoxicity, and pathways connected with some neurodegenerative or autoimmune diseases.

\begin{tabular}{|c|c|c|c|c|c|}
\hline KEGG ID & KEGG path & $N_{\text {sig }}$ & $N_{\text {path }}$ & FDR & Status \\
\hline hsa05169 & Epstein-Barr virus infection & 198 & NA & $1.31 e-10$ & Inhibited \\
\hline hsa04612 & Antigen processing and presentation & 75 & 107 & $3.71 e-05$ & Activated \\
\hline hsa05203 & Viral carcinogenesis & 205 & NA & $3.71 e-05$ & Activated \\
\hline hsa04510 & Focal adhesion & 201 & 329 & $3.98 e-05$ & Activated \\
\hline hsa04810 & Regulation of actin cytoskeleton & 212 & 322 & $3.98 e-05$ & Activated \\
\hline hsa03013 & RNA transport & 151 & 202 & $5.64 e-05$ & Inhibited \\
\hline hsa05168 & Herpes simplex infection & 184 & NA & $5.64 e-05$ & Activated \\
\hline hsa05164 & Influenza A & 173 & NA & 0.00019 & Activated \\
\hline hsa05323 & Rheumatoid arthritis & 91 & 119 & 0.000218 & Inhibited \\
\hline hsa05140 & Leishmaniasis & 72 & 99 & 0.000218 & Activated \\
\hline hsa05012 & Parkinson's disease & 111 & 138 & 0.000367 & Inhibited \\
\hline hsa05166 & HTLV-I infection & 260 & NA & 0.000542 & Activated \\
\hline hsa05110 & Vibrio cholerae infection & 54 & 90 & $6.00 e-04$ & Activated \\
\hline hsa05322 & Systemic lupus erythematosus & 131 & 137 & 0.00269 & Activated \\
\hline hsa04062 & Chemokine signaling pathway & 188 & 268 & 0.00287 & Activated \\
\hline hsa05130 & Pathogenic Escherichia coli infection & 54 & 88 & 0.00334 & Activated \\
\hline hsa04914 & Progesterone-mediated oocyte maturation & 86 & 152 & 0.00334 & Inhibited \\
\hline hsa05016 & Huntington's disease & 168 & 218 & 0.00381 & Inhibited \\
\hline hsa05134 & Legionellosis & 55 & NA & 0.00389 & Inhibited \\
\hline hsa04670 & Leukocyte transendothelial migration & 115 & 175 & 0.00484 & Inhibited \\
\hline hsa05416 & Viral myocarditis & 70 & 107 & 0.0118 & Activated \\
\hline hsa05131 & Shigellosis & 61 & 112 & 0.0133 & Activated \\
\hline hsa05152 & Tuberculosis & 179 & NA & 0.0133 & Activated \\
\hline hsa04141 & Protein processing in endoplasmic reticulum & 163 & 236 & 0.0172 & Activated \\
\hline hsa05100 & Bacterial invasion of epithelial cells & 70 & 123 & 0.0236 & Activated \\
\hline hsa04660 & $\mathrm{T}$ cell receptor signaling pathway & 108 & 169 & 0.0266 & Activated \\
\hline hsa05145 & Toxoplasmosis & 133 & 193 & 0.027 & Inhibited \\
\hline hsa05150 & Staphylococcus aureus infection & 55 & 62 & 0.027 & Activated \\
\hline hsa04540 & Gap junction & 89 & 130 & 0.027 & Activated \\
\hline hsa05032 & Morphine addiction & 92 & NA & 0.027 & Activated \\
\hline hsa04940 & Type I diabetes mellitus & 43 & 54 & 0.0303 & Inhibited \\
\hline hsa04380 & Osteoclast differentiation & 132 & 193 & 0.0346 & Activated \\
\hline hsa04650 & Natural-killer-cell-mediated cytotoxicity & 134 & 189 & 0.0346 & Inhibited \\
\hline hsa05120 & Epithelial cell signaling in Helicobacter pylori infection & 68 & 100 & 0.0361 & Activated \\
\hline hsa03018 & RNA degradation & 69 & 97 & 0.0475 & Inhibited \\
\hline
\end{tabular}

$N_{\text {sig }}$ : number of significantly changed genes in the pathway; $N_{\text {path }}$ : number of genes in the pathway; FDR: false discovery rate.

concerned, we detected a significant difference in expression of $\mathrm{Bcl}-2$ and $\mathrm{Bcl}-\mathrm{XL}$ transcripts in the treated-control group $(\mathrm{Bcl}-2, P=0.004, \log \mathrm{FC}=-1.21 ; \mathrm{Bcl}-\mathrm{XL}, P=0.006$, $\log \mathrm{FC}=1.67)$. Overexpression of $\mathrm{Bcl}-\mathrm{XL}$ in the treated group was evident and was 3.5 times higher than in the control group. In contrast, we did not detect a significant difference in expression of $\mathrm{Bcl}-2$ family proteins in the cancer-control group (Bcl-2, $P=0.085 ; \mathrm{Bcl}-\mathrm{XL}, P=0.14$ ). In some studies overexpression of the antiapoptotic proteins $\mathrm{Bcl}-2$ and $\mathrm{Bcl}-\mathrm{XL}$ is associated with chemotherapy and radiation resistance $[53,54]$, and the combination of $\mathrm{p} 53$ status and $\mathrm{Bcl}$ $\mathrm{XL}$ is associated with cisplatin resistance in HNSCC cells in vitro $[55,56]$. The combination of low p53 and high Bcl-XL expression is associated with poor overall survival and disease specific survival $[55,57]$. The negligible effect of HNSCC treatment on the activity of the above-mentioned genes, based on the level of cRNA, can be interpreted according to our recent results demonstrating differentiation-dependent 


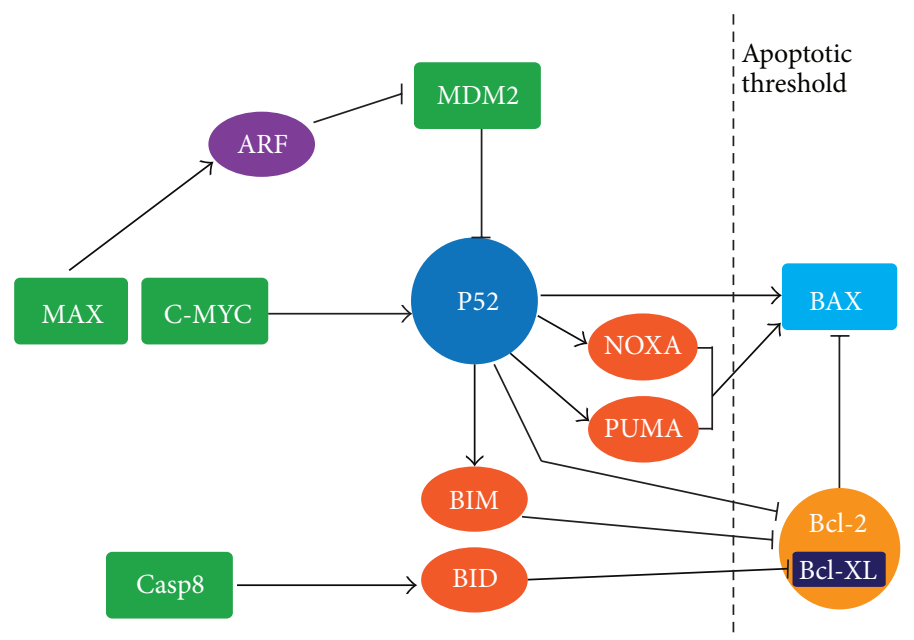

FIGURE 2: Role of p53 and other proteins (BH3 family, Bcl-2 family) in the apoptotic pathway.

expression of the endogenous lectin galectin-9 in normal squamous cell epithelium and in cancer [58]. Although normal squamous epithelium from noncancer patients demonstrated strictly basal cell expression, the malignant epithelium of tumours and a significant amount of histologically normal epithelium from HNSCC patients were devoid of expression of this lectin. This indicates some abnormality of histologically normal epithelial layer. These data suggest that the normal epithelium is damaged at the molecular level but to a lesser extent and complexity than is necessary for tumour formation. It harmonizes with hypothesis about field cancerisation [59].

Included in the apoptotic load are a number of $\mathrm{BH} 3-$ only proteins that show no obvious regulation by $\mathrm{p} 53$ yet antagonise $\mathrm{Bcl}-2$ function in response to specific cellular stresses (Figure 2). First, the BH3-only proteins Bim, Bad, and Hrk are induced by cytokine deprivation in a p53independent manner [60], yet these proteins may synergize with p53-induced pathways to overcome the antiapoptotic threshold set by Bcl-2 and promote cell death. Second, deregulated Myc expression promotes p53-dependent apoptosis [61], but it also promotes the p53-independent activation of the proapoptotic BH3-only proteins Bim and Bax [62, 63]. Thus, p53-dependent and -independent signals act in parallel to promote cell death and suppress tumourigenesis. The combined strength of these signals is required to overwhelm the antiapoptotic Bcl-2 family members such that inactivation of any one of several prodeath effectors can drop the system below its apoptotic firing threshold and allow unabated proliferation. Myc is an important factor which regulates the expression of cellular targets involved in a wide range of diverse cellular functions, including cell growth, proliferation, loss of cell-cell contact, loss of differentiation, and angiogenesis. In our study we showed deregulated Myc expression in serum of HNSCC patients. Activation of Myc has been shown to cause cell growth, loss of differentiation, and cell cycle entry in suprabasal keratinocytes in vivo [64].

Our hypothesis is that apoptosis is altered in cancer patients due to resistance of $\mathrm{Bcl}-\mathrm{XL}$ to p53-independent stimulation by Myc (MAX), potentially Bax, or other BH3only proteins. The mechanisms of action of $\mathrm{Bcl}-2$ and $\mathrm{Bcl}-$ $\mathrm{XL}$ are complex, with many postulated interactions with other proteins, and the role of any single interaction in the final phenotype at cellular level remains ill-defined. In some studies Bcl-XL has been $~ 10$ times more active than Bcl-2 in repressing apoptosis in breast cancer cell lines [65]. When examined in the same cellular context, Bcl-2 and Bcl-XL differ substantially in the potency with which they inhibit apoptosis, mediated in part by differences in the inhibition of specific subcellular pathways.

Concerning the global difference in presence of transcripts in same patients before and one year after treatment, the principal component analysis (PCA) showed positive shift in treated patients in higher presence of transcripts corresponding more with the population of healthy individuals (see Figure 1(a)). This time period was not sufficient to make definite conclusions because some residual disease was present or patients underwent radical oncological treatment and the organism is not balanced yet. Nevertheless, there was a positive shift in PCA, which demonstrated that this method could be beneficial in the control of tumour recurrence.

The convergence of $\mathrm{p} 53$ on various aspects of $\mathrm{Bcl}-2$ biology highlights the crucial role of this interaction in tumour suppression and drug response. Thus, promoting the p53-Bcl-2 interaction seemingly provides an ideal strategy for anticancer therapy. The relevance of specific p53-induced effector proteins and antiapoptotic Bcl-2 family members may vary in distinct tumourigenic contexts; therefore, understanding the precise apoptotic pathways abrogated in specific malignancies will be essential for devising targeted proapoptotic therapy. This includes expanding our understanding of how parallel apoptotic pathways synergise with p53-Bcl-2 signalling to promote cell death. We assumed that in cells the essential difference between Bcl-2 and Bcl-XL involved regulation of expression, probably due to expression in different tissues or in the same tissue but at different times.

We suggest that microchip analysis of serum cRNA in patients with HNSCC should be suitable for refinement of 
early stage diagnosis of disease that could be important for development of new personalised strategies in diagnosis and treatment of tumours. Either analysis of serum specimens of patients one year after treatment shows promising results in the meaning of shift to the population of healthy individuals.

\section{Supporting Information}

Additional supporting information may be found in the online version of this paper.

\section{Conflict of Interests}

The authors declare that there is no conflict of interests regarding the publication of this paper.

\section{Authors' Contribution}

Markéta Čapková and Jana Šáchová contributed equally to this work.

\section{Acknowledgments}

This work was supported by the Ministry of Health of the Czech Republic no. NT13488, UNCE 204013, GAUK 291811, GAUK 60608, PRVOUK 27-1 OnkoKom, and SVV264-510. Special thanks are due to Genomics and Bioinformatics Core Facility Center of Institute of Molecular Genetics, Academy of Sciences of the Czech Republic, especially to Martina Chmelíková, for acquisition of microarray data, and to the Department of Immunology of Second Faculty of Medicine, Charles University in Prague, especially to Jitka Fučíková and Hana Ulčová, for serum samples processing.

\section{References}

[1] J. Ferlay, P. Autier, M. Boniol, M. Heanue, M. Colombet, and P. Boyle, "Estimates of the cancer incidence and mortality in Europe in 2006," Annals of Oncology, vol. 18, no. 3, pp. 581-592, 2007.

[2] C.-J. Liu, T.-Y. Liu, L.-T. Kuo et al., "Differential gene expression signature between primary and metastatic head and neck squamous cell carcinoma," Journal of Pathology, vol. 214, no. 4, pp. 489-497, 2008.

[3] P. Garzino-Demo, A. Dell'Acqua, P. Dalmasso et al., "Clinicopathological parameters and outcome of 245 patients operated for oral squamous cell carcinoma," Journal of CranioMaxillofacial Surgery, vol. 34, no. 6, pp. 344-350, 2006.

[4] K. Imre, E. Pinar, S. Oncel, C. Calli, and B. Tatar, "Predictors of extracapsular spread in lymph node metastasis," European Archives of Oto-Rhino-Laryngology, vol. 265, no. 3, pp. 337-339, 2008.

[5] S. K. Puri, C.-Y. Fan, and E. Hanna, "Significance of extracapsular lymph node metastases in patients with head and neck squamous cell carcinoma," Current Opinion in Otolaryngology and Head and Neck Surgery, vol. 11, no. 2, pp. 119-123, 2003.

[6] J. Han, M. Kioi, W.-S. Chu, J. L. Kasperbauer, S. E. Strome, and R. K. Puri, "Identification of potential therapeutic targets in human head \& neck squamous cell carcinoma," Head \& Neck Oncology, vol. 1, article 27, 2009.
[7] D. Chin, G. M. Boyle, R. M. Williams et al., "Novel markers for poor prognosis in head and neck cancer," International Journal of Cancer, vol. 113, no. 5, pp. 789-797, 2005.

[8] P. Choi and C. Chen, "Genetic expression profiles and biologic pathway alterations in head and neck squamous cell carcinoma," Cancer, vol. 104, pp. 1113-1128, 2005.

[9] A. Cromer, A. Carles, R. Millon et al., "Identification of genes associated with tumorigenesis and metastatic potential of hypopharyngeal cancer by microarray analysis," Oncogene, vol. 23, no. 14, pp. 2484-2498, 2004.

[10] F. Lemaire, R. Millon, J. Young et al., "Differential expression profiling of head and neck squamous cell carcinoma (HNSCC)," British Journal of Cancer, vol. 89, no. 10, pp. 1940-1949, 2003.

[11] P. K. Ha, S. S. Chang, C. A. Glazer, J. A. Califano, and D. Sidransky, "Molecular techniques and genetic alterations in head and neck cancer," Oral Oncology, vol. 45, no. 4-5, pp. 335339, 2009.

[12] A. J. Wieczorek, V. Sitaramam, W. Machleidt, K. Rhyner, A. P. Perruchoud, and L. H. Block, "Diagnostic and prognostic value of RNA-proteolipid in sera of patients with malignant disorders following therapy: first clinical evaluation of a novel tumor marker," Cancer Research, vol. 47, no. 23, pp. 6407-6412, 1987.

[13] S. C. Wong, S. F. Lo, M. T. Cheung et al., "Quantification of plasma $\beta$-catenin mRNA in colorectal cancer and adenoma patients," Clinical Cancer Research, vol. 10, no. 5, pp. 1613-1617, 2004.

[14] D.-C. Chu, C.-K. Chuang, Y.-F. Liou, R.-D. Tzou, H.-C. Lee, and C.-F. Sun, "The use of real-time quantitative PCR to detect circulating prostate-specific membrane antigen mRNA in patients with prostate carcinoma," Annals of the New York Academy of Sciences, vol. 1022, pp. 157-162, 2004.

[15] X. Q. C. Chen, H. Bonnefoi, M.-F. Pelte et al., "Telomerase RNA as a detection marker in the serum of breast cancer patients," Clinical Cancer Research, vol. 6, no. 10, pp. 3823-3826, 2000.

[16] E. Sueoka, N. Sueoka, K. Iwanaga et al., "Detection of plasma hnRNP B1 mRNA, a new cancer biomarker, in lung cancer patients by quantitative real-time polymerase chain reaction," Lung Cancer, vol. 48, no. 1, pp. 77-83, 2005.

[17] M. S. Silva, R. L. da Silva Sá, M. L. Fagundes et al., "Contribution of the electrophysiological and anatomical analysis of the atypical atrioventricular nodal tachycardia circuit," Arquivos Brasileiros de Cardiologia, vol. 88, no. 2, pp. 124-151, 2007.

[18] R. M. Johnstone, "Revisiting the road to the discovery of exosomes," Blood Cells, Molecules, and Diseases, vol. 34, no. 3, pp. 214-219, 2005.

[19] E. Papadopoulou, E. Davilas, V. Sotiriou et al., "Cell-free DNA and RNA in plasma as a new molecular marker for prostate cancer," Oncology Research, vol. 14, no. 9, pp. 439-445, 2004.

[20] D. O. Hasselmann, G. Rappl, M. Rossler, S. Ugurel, W. Tilgen, and U. Reinhold, "Detection of tumor-associated circulating mRNA in serum, plasma and blood cells from patients with disseminated malignant melanoma," Oncology Reports, vol. 8, pp. 115-118, 2001.

[21] N. Miura, G. Shiota, T. Nakagawa et al., "Sensitive detection of human telomerase reverse transcriptase mRNA in the serum of patients with hepatocellular carcinoma," Oncology, vol. 64, no. 4, pp. 430-434, 2003.

[22] M. Urbanova, J. Plzak, H. Strnad, and J. Betka, "Circulating nucleic acids as a new diagnostic tool," Cellular and Molecular Biology Letters, vol. 15, no. 2, pp. 242-259, 2010. 
[23] L. O’Driscoll, E. Kenny, J. P. Mehta et al., "Feasibility and relevance of global expression profiling of gene transcripts in serum from breast cancer patients using whole genome microarrays and quantitative RT-PCR," Cancer Genomics and Proteomics, vol. 5, no. 2, pp. 95-104, 2008.

[24] H. Schwarzenbach, D. S. B. Hoon, and K. Pantel, "Cell-free nucleic acids as biomarkers in cancer patients," Nature Reviews Cancer, vol. 11, no. 6, pp. 426-437, 2011.

[25] M. J. Dunning, M. L. Smith, M. E. Ritchie, and S. Tavaré, "Beadarray: R classes and methods for Illumina bead-based data," Bioinformatics, vol. 23, no. 16, pp. 2183-2184, 2007.

[26] G. K. Smyth, J. Michaud, and H. S. Scott, "Use of withinarray replicate spots for assessing differential expression in microarray experiments," Bioinformatics, vol. 21, no. 9, pp. 2067-2075, 2005.

[27] R package, illuminaHumanv3BeadID.db.

[28] A. L. Tarca, S. Draghici, P. Khatri et al., "A novel signaling pathway impact analysis," Bioinformatics, vol. 25, no. 1, pp. 7582, 2009.

[29] C. Chen, E. Méndez, J. Houck et al., "Gene expression profiling identifies genes predictive of oral squamous cell carcinoma," Cancer Epidemiology Biomarkers and Prevention, vol. 17, no. 8, pp. 2152-2162, 2008.

[30] Y. Li, D. Elashoff, M. Oh et al., "Serum circulating human mRNA profiling and its utility for oral cancer detection," Journal of Clinical Oncology, vol. 24, no. 11, pp. 1754-1760, 2006.

[31] L. Lacina, B. Dvořánkova, K. Smetana Jr. et al., "Marker profiling of normal keratinocytes identifies the stroma from squamous cell carcinoma of the oral cavity as a modulatory microenvironment in co-culture," International Journal of Radiation Biology, vol. 83, no. 11-12, pp. 837-848, 2007.

[32] J. Klíma, L. Lacina, B. Dvořánková et al., "Differential regulation of galectin expression/reactivity during wound healing in porcine skin and in cultures of epidermal cells with functional impact on migration," Physiological Research, vol. 58, no. 6, pp. 873-884, 2009.

[33] B. Dvorankova, P. Szabo, L. Lacina, O. Kodet, E. Matouskova, and K. Smetana Jr., "Fibroblasts prepared from different types of malignant tumors stimulate expression of luminal marker keratin 8 in the EM-G3 breast cancer cell line," Histochemistry and Cell Biology, vol. 137, no. 5, pp. 679-685, 2012.

[34] H. Strnad, L. Lacina, M. Kolář et al., "Head and neck squamous cancer stromal fibroblasts produce growth factors influencing phenotype of normal human keratinocytes," Histochemistry and Cell Biology, vol. 133, no. 2, pp. 201-211, 2010.

[35] J. Valach, Z. Fík, H. Strnad et al., "Smooth muscle actinexpressing stromal fibroblasts in head and neck squamous cell carcinoma: increased expression of galectin-1 and induction of poor prognosis factors," International Journal of Cancer, vol. 131, pp. 2499-2508, 2012.

[36] V. Swarup and M. R. Rajeswari, "Circulating (cell-free) nucleic acids: a promising, non-invasive tool for early detection of several human diseases," FEBS Letters, vol. 581, no. 5, pp. 795799, 2007.

[37] X. Q. Chen, H. Bonnefoi, S. Diebold-Berger et al., "Detecting tumor-related alterations in plasma or serum DNA of patients diagnosed with breast cancer," Clinical Cancer Research, vol. 5, no. 9, pp. 2297-2303, 1999.

[38] H. Nawroz, W. Koch, P. Anker, M. Stroun, and D. Sidransky, "Microsatellite alterations in serum DNA of head and neck cancer patients," Nature Medicine, vol. 2, no. 9, pp. 1035-1037, 1996.
[39] J. O. Humtsoe, E. Koya, E. Pham et al., “Transcriptional profiling identifies upregulated genes following induction of epithelialmesenchymal transition in squamous carcinoma cells," Experimental Cell Research, vol. 318, no. 4, pp. 379-390, 2012.

[40] T. J. Molloy, P. Roepman, B. Naume, and L. J. van't Veer, "A prognostic gene expression profile that predicts circulating tumor cell presence in breast cancer patients," PLoS ONE, vol. 7, no. 2, Article ID e32426, 2012.

[41] C. Oliveras-Ferraros, A. Vazquez-Martin, B. Queralt et al., "Interferon/STAT1 and neuregulin signaling pathways are exploratory biomarkers of cetuximab (Erbitux®) efficacy in KRAS wild-type squamous carcinomas: a pathway-based analysis of whole human-genome microarray data from cetuximabadapted tumor cell-line models," International Journal of Oncology, vol. 39, no. 6, pp. 1455-1479, 2011.

[42] G. Heller, M. Weinzierl, C. Noll et al., "Genome-wide miRNA expression profiling identifies miR-9-3 and miR-193a as targets for DNA methylation in non-small cell lung cancers," Clinical Cancer Research, vol. 18, no. 6, pp. 1619-1629, 2012.

[43] D. R. de la Blétière, O. Blanchet, P. Cornillet-Lefèbvre et al., "Routine use of microarray-based gene expression profiling to identify patients with low cytogenetic risk acute myeloid leukemia: accurate results can be obtained even with suboptimal samples," BMC Medical Genomics, vol. 5, article 6, 2012.

[44] A. Simons, M. Stevens-Kroef, N. El Idrissi-Zaynoun et al., "Microarray-based genomic profiling as a diagnostic tool in acute lymphoblastic leukemia," Genes Chromosomes and Cancer, vol. 50, no. 12, pp. 969-981, 2011.

[45] J. A. Harris, S. Jain, Q. Ren, A. Zarineh, C. Liu, and S. Ibrahim, "CD163 versus CD68 in tumor associated macrophages of classical hodgkin lymphoma," Diagnostic Pathology, vol. 7, no. 1, article 12, 2012.

[46] M. T. Hemann and S. W. Lowe, “The p53-Bcl-2 connection," Cell Death and Differentiation, vol. 13, no. 8, pp. 1256-1259, 2006.

[47] L. D. Attardi and L. A. Donehower, "Probing p53 biological functions through the use of genetically engineered mouse models," Mutation Research: Fundamental and Molecular Mechanisms of Mutagenesis, vol. 576, no. 1-2, pp. 4-21, 2005.

[48] D. R. Green, "Apoptotic pathways: ten minutes to dead," Cell, vol. 121, no. 5, pp. 671-674, 2005.

[49] D. R. Green and G. Kroemer, "The pathophysiology of mitochondrial cell death," Science, vol. 305, no. 5684, pp. 626-629, 2004.

[50] S. Cory and J. M. Adams, "Killing cancer cells by flipping the Bcl-2/Bax switch," Cancer Cell, vol. 8, no. 1, pp. 5-6, 2005.

[51] D. Hockenbery, G. Nunez, C. Milliman, R. D. Schreiber, and S. J. Korsmeyer, "Bcl-2 is an inner mitochondrial membrane protein that blocks programmed cell death," Nature, vol. 348, no. 6299, pp. 334-336, 1990.

[52] S. W. Lowe, E. Cepero, and G. Evan, "Intrinsic tumour suppression,” Nature, vol. 432, no. 7015, pp. 307-315, 2004.

[53] J. C. de Vicente, L. M. J. Gutiérrez, A. H. Zapatero, M. F. F. Forcelledo, G. Hernández-Vallejo, and J. S. López Arranz, "Prognostic significance of p53 expression in oral squamous cell carcinoma without neck node metastases," Head and Neck, vol. 26, no. 1, pp. 22-30, 2004.

[54] B. Khademi, F. M. Shirazi, M. Vasei et al., "The expression of p53, c-erbB-1 and c-erbB-2 molecules and their correlation with prognostic markers in patients with head and neck tumors," Cancer Letters, vol. 184, no. 2, pp. 223-230, 2002. 
[55] J. A. Bauer, D. K. Trask, B. Kumar et al., "Reversal of cisplatin resistance with a $\mathrm{BH} 3$ mimetic, (-)-gossypol, in head and neck cancer cells: role of wild-type p53 and Bcl-xL," Molecular Cancer Therapeutics, vol. 4, no. 7, pp. 1096-1104, 2005.

[56] Y. Yamano, K. Uzawa, K. Saito et al., "Identification of cisplatinresistance related genes in head and neck squamous cell carcinoma," International Journal of Cancer, vol. 126, no. 2, pp. 437-449, 2010.

[57] J. A. Bauer, B. Kumar, K. G. Cordell et al., “Targeting apoptosis to overcome cisplatin resistance: a translational study in head and neck cancer," International Journal of Radiation Oncology Biology Physics, vol. 69, no. 2, pp. S106-S108, 2007.

[58] Z. Fik, J. Valach, M. Chovanec et al., "Loss of adhesion/growthregulatory galectin-9 from squamous cell epithelium in head and neck carcinomas," Journal of Oral Pathology and Medicine, vol. 42, no. 2, pp. 166-173, 2013.

[59] P. K. Ha and J. A. Califano, "The molecular biology of mucosal field cancerization of the head and neck," Critical Reviews in Oral Biology and Medicine, vol. 14, no. 5, pp. 363-369, 2003.

[60] S. N. Willis and J. M. Adams, "Life in the balance: how BH3-only proteins induce apoptosis," Current Opinion in Cell Biology, vol. 17, no. 6, pp. 617-625, 2005.

[61] H. Hermeking and D. Eick, "Mediation of c-myc-induced apoptosis by p53," Science, vol. 265, no. 5181, pp. 2091-2093, 1994.

[62] A. Egle, A. W. Harris, P. Bouillet, and S. Cory, "Bim is a suppressor of Myc-induced mouse B cell leukemia," Proceedings of the National Academy of Sciences of the United States of America, vol. 101, no. 16, pp. 6164-6169, 2004.

[63] S. N. Willis, L. Chen, G. Dewson et al., "Proapoptotic Bak is sequestered by $\mathrm{Mcl}-1$ and $\mathrm{Bcl}-\mathrm{xL}$, but not Bcl-2, until displaced by BH3-only proteins," Genes and Development, vol. 19, no. 11, pp. 1294-1305, 2005.

[64] S. C. Robson, L. Ward, H. Brown et al., "Deciphering c-MYCregulated genes in two distinct tissues," BMC Genomics, vol. 12, article 476, 2011.

[65] A. A. Fiebig, W. Zhu, C. Hollerbach, B. Leber, and D. W. Andrews, "Bcl-XL is qualitatively different from and ten times more effective than Bcl-2 when expressed in a breast cancer cell line," BMC Cancer, vol. 6, article 213, 2006. 


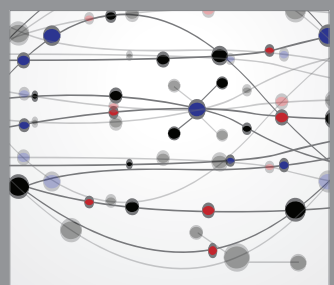

The Scientific World Journal
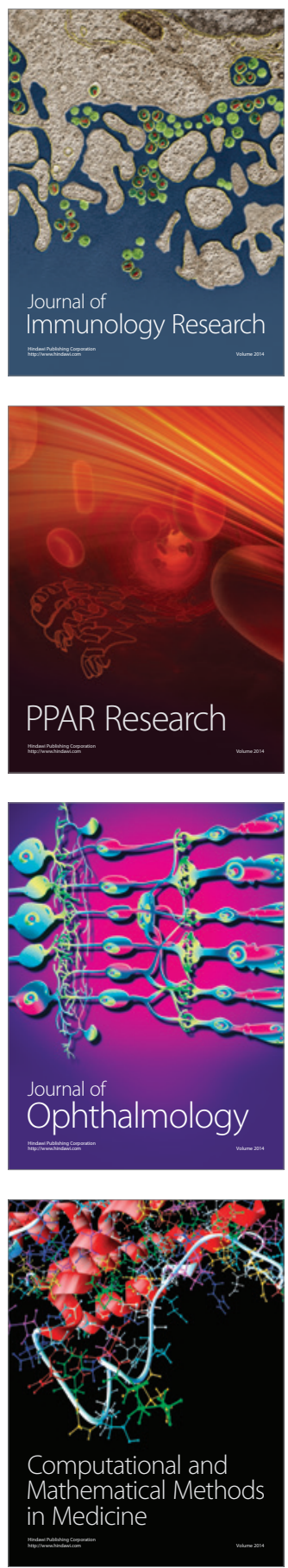

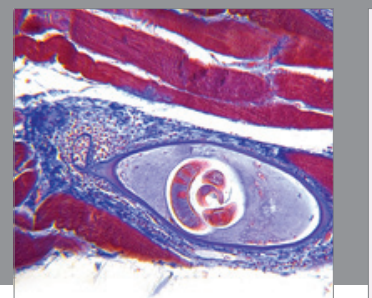

Gastroenterology

Research and Practice
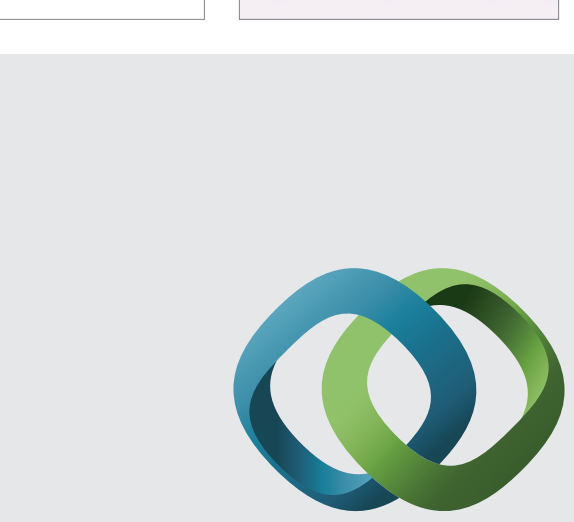

\section{Hindawi}

Submit your manuscripts at

http://www.hindawi.com
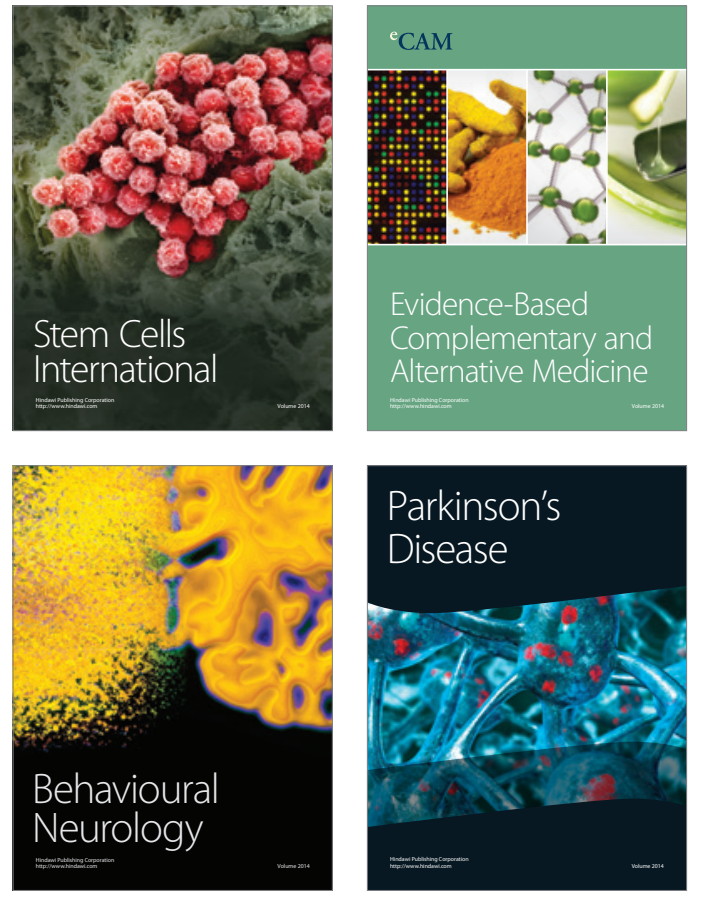
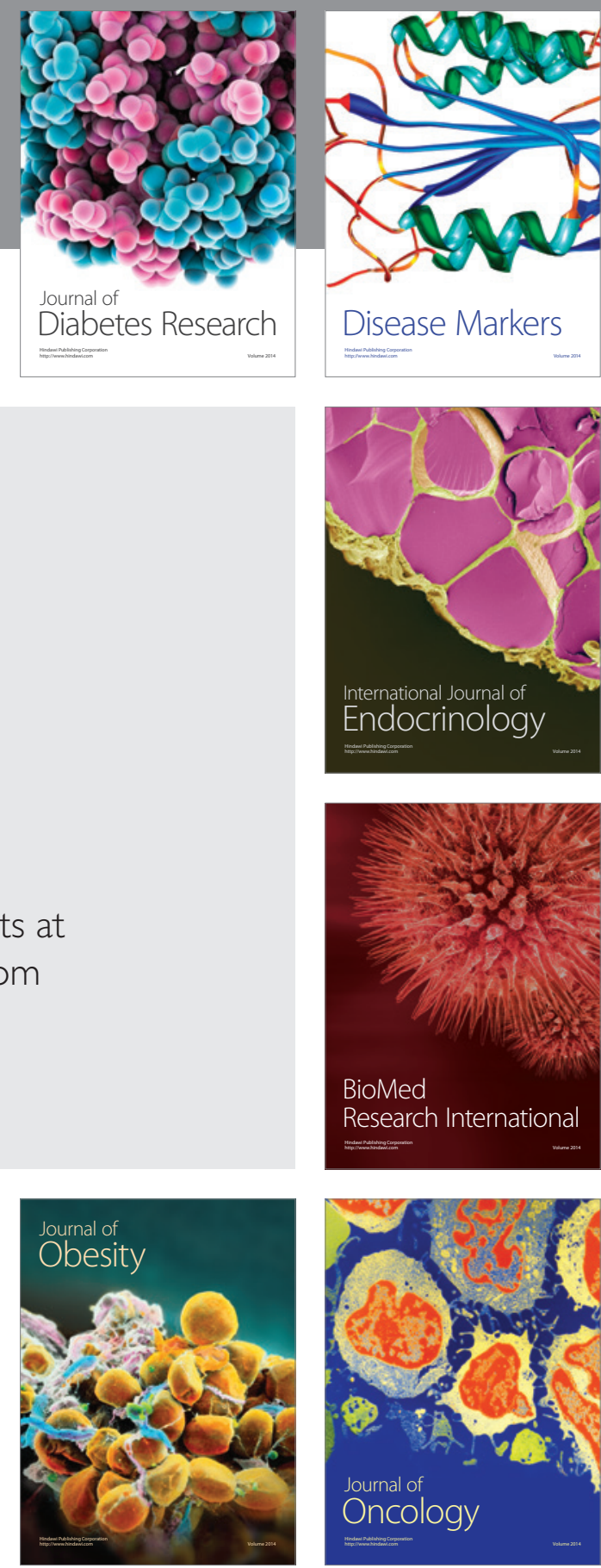

Disease Markers
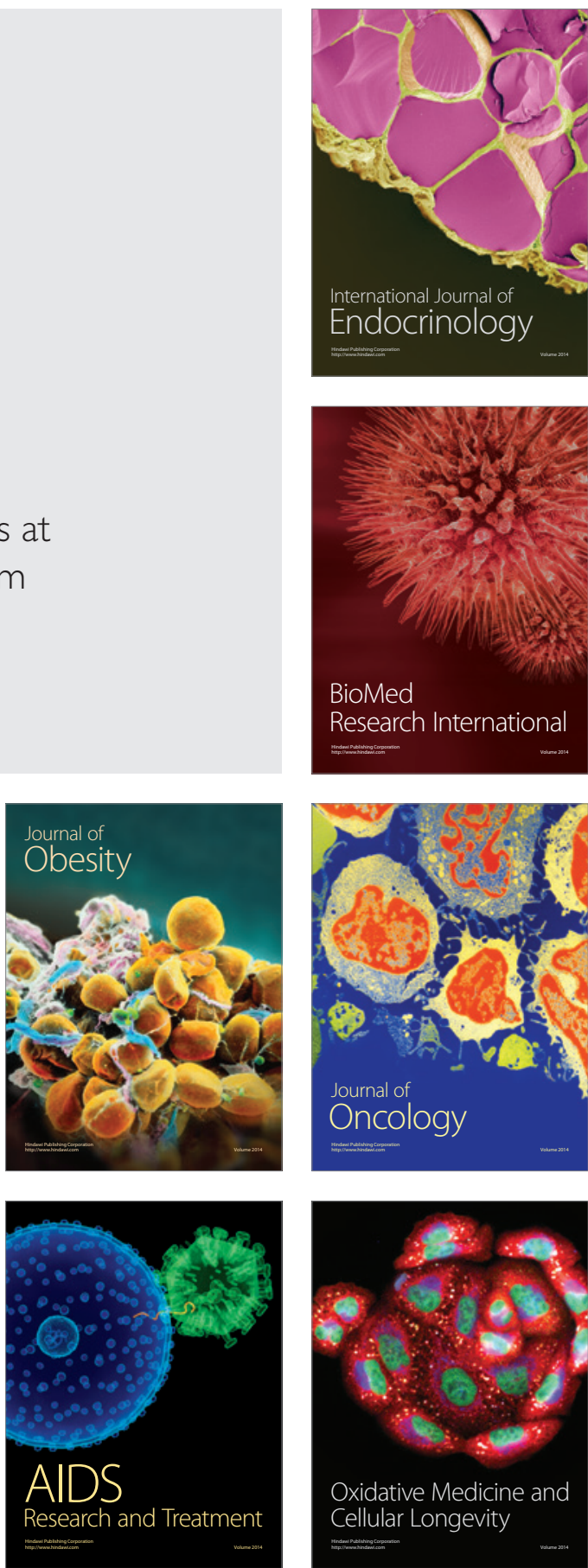